\title{
Comparison between conventional and harmonic techniques in bleeding control during Thyroidectomy
}

\author{
Saqib Shakoor ${ }^{1}$, M Asfand Yar $^{2}$, Burhan Nawaz \\ 1,2,3. House Officer Bahawal Victoria Hospital, Bahawalpur \\ Corresponding Author:shazzzsaqib@gmail.com
}

\begin{abstract}
:
Objective: The basic aim of this study is to find out comparison between conventional and harmonic techniques in bleeding control during Thyroidectomy.

Methodology: This randomized control trial was conducted in Surgery Department, Bahawal Victoria Hospital Bahawalpur. This study was completed in 5 months (August 2018 to January 2019) and all the patients under trial were asked for informed consent. A total number of $100 \%(\mathrm{n}=62)$ were taken in this trial and online source Openepi.com was used for calculating sample size. Patients were selected by lottery method. Computer software SPSS version 23.2 was used for complete data entry and analysis. All the descriptive variables like onset of action and age were presented as SD and mean. Statistical test ANOVA was applied to find the significance among all groups. Chi square test was applied for analysis of continuous stats among groups. P value 0.05 was to be considered as significant.
\end{abstract}

Result: A total number of $100 \%(n=62)$ patients were included, divided into two equal groups, 31 in each i.e. harmonic scalpel and conventional knot groups. The mean age of the patients, in harmonic scalpel group, was $45.29 \pm 4.56$ years. There were $64.5 \%(n=20)$ males and $35.5 \%(n=11)$ females. The mean age of the patients, in conventional knot, was $44.96 \pm 2.97$ years. There were $74.2 \%(n=23)$ males and $25.8 \%(n=8)$ females. No significant difference was found for age $(\mathrm{t}=0.329, \mathrm{p}=0.743)$ and gender $\left(\chi^{2}=0.683, \mathrm{p}=0.409\right)$ in groups. The main outcome variables of this study were the time of procedure (minutes) and blood loss volume (ml). The mean time of procedure was $98.80 \pm 16.52$ minutes and 119.81 \pm 9.95 minutes for the harmonic scalpel and conventional knot groups respectively. Significant difference was found for the time of procedure in groups $(\mathrm{t}=-6.060$, $\mathrm{p}$-value $=$ $0.000)$.

Conclusion: The whole study can be ended with this conclusion that the harmonic scalpel is more effective than the conventional method of ligation or knotting in thyroidectomy. Its use offer many clinical benefits including reduction in time of surgery and blood volume as well.

Keywords: Thyroidectomy, Harmonic, Conventional and Bleeding control.

DOI: $10.7176 / \mathrm{JMPB} / 54-09$

Publication date: April $30^{\text {th }} 2019$

\section{Introduction:}

The description about the thyroid gland is very prehistoric' for the first time it was name as "shield shape gland" by the Romans ${ }^{[1]}$. In the literature during $12^{\text {th }}$ or $13^{\text {th }}$ century not only the thyroid masses were mentioned but in 1170 Robert Frugard explained the complication of goiter. Thyroid surgery was begun in $12^{\text {th }}$ century by using hot iron, Setons and caustics powers (most results were fatal).At that time, the major advancement was, antisepsis, artery forceps and anesthesia to be practice ${ }^{[2]}$. The pioneers of thyroid surgery, Theodor Koches and Theodor Billroth, formulated many acceptable techniques of thyroid surgery between the year 1873 and $1883^{[3]}$ In conventional method knot tying and ligation were important process. The very important thing of this operation is that the thyroid gland is one of the highly vascularized among all the organs having rich blood vessels and plexuses present in the parenchyma. This needs to be controlled by ligatures ${ }^{[4]}$. The ligation and division of these vessels is time consuming. On other hand modern techniques involve harmonic scalpel (in this case a device of high frequency range $55.5 \mathrm{hz}$ is used for cut and coagulate tissue at same time) and thyroidectomy The only change that has brought in this mechanism is only the choice of certain type of operation i.e. lobectomy, total thyroidectomy, subtotal thyroidectomy for a given diagnosis. Some other methods related to this are nerve stimulation, and hypnosis for anesthesia. However all these are not widely accepted ${ }^{[5]}$. 
Thyroidectomy is, in essence, devascularization of thyroid by double ligation and dividing the branches of thyroid vessels followed by excision of the gland, and done when a patient is suffering from thyroid cancer, goiter or hyperthyroidism, the endocrine surgeons often perform the procedure of thyroidectomy. Since time spent in the operative room is expensive, this will reduce both time and cost of operation ${ }^{[6]}$. From the experience, we can conclude that during thyroid surgery, the use of harmonic scalpel reduce the time duration much more, and also report initial case controlled study results by comparing the use of conventional suture tying to the harmonic scalpel in patient undergone by total thyroidectomy or lobectomy ${ }^{[7]}$.

The procedures included in thyroidectomy have many complications like massive bleeding, injury and infection to the surrounding organs and structure ${ }^{[8]}$. Similarly, all of the complications are directly related to mortality and morbidity rates of $40 \% \mathrm{app}^{[9]}$.

That's why thyroid surgery is considered as barbaric and called as "horrid butchery".

The previous studies shows that blood volume and surgery time by using harmonic scalpel method is less as compared to conventional knots method, but we want to compare blood volume and time of surgery by using both harmonic and conventional methods on local level ${ }^{[10]}$.

\section{Method and material:}

After taking the ethical approval from the ethics committee of the institution, this randomized control trial was conducted in Surgery Department, Bahawal Victoria Hospital Bahawalpur. This study was completed in 5 months (August 2018 to January 2019) and all the patients under trial were asked for informed consent. Patients were also completely briefed about their participation in study, its procedure and its purpose also. A total number of $100 \%(n=62)$ were taken in this trial and online source Openepi.com was used for calculating sample size. Those patients, who had to undergo total thyroidectomy for multinodular disease, were in inclusion criteria and those patients who were suffering from toxic disease, intrathoracic goiter, malignant disease and wanted central or lateral lymphadenectomy were excluded from the study. Patients were selected by using lottery method.

For this process, a total number of $100 \%(\mathrm{n}=62)$ patients were used and these patients were divided into two groups and each group consists of $50 \%(\mathrm{n}=31)$ patients, in 62 member there were $65 \%$ male and $35 \%$ females. All patients were given routine preoperative measures for their disease and same type of anesthesia and hospital care was applied but surgical instruments used were different. All the patients for operation were admitted in morning and they were kept there for 23 hours. During the procedure anesthesia used was endotracheal general anesthesia. During operation conventional methods was used to position and cover or drapes the body of patient. Usually depends upon the size of thyroid of patient a cut of 4 to $6 \mathrm{~cm}$ was made with help of scalpel which is also called incision, exactly over the level of thyroid isthmus. The strap muscles that surround the thyroid gland laterally and on midline were separated .Either by using conventional knot tying or harmonic knot tying the superior, inferior and middle thyroid vessels were categorized separately. During process different vessels are displaced, suppose first thyroid lobe is medially rotated and then the vessel of ligament of berry, after that the nerves that are visible or present near the lobe is clamped and tie together. The same mechanism is repeated on lobe of counter side. Finally when the ligation gets completed the wound is closed by using the interrupted 3-o polyglactin suture to give accurate position to strap muscles which were displaced before the operation. Then Michel clips are used to close the skin which was removed before operation on day 1.

Computer software SPSS version 23.2 was used for complete data entry and analysis. All the descriptive variables like onset of action and age were presented as SD and mean. Statistical test ANOVA was applied to find the significance among all groups. Chi square test was applied for analysis of continuous stats among groups. $\mathrm{P}$ value 0.05 was to be considered as significant.

\section{RESULT:}

In this study, a total number of $100 \%(n=62)$ patients were included, divided into two equal groups, 31 in each i.e. harmonic scalpel and conventional knot groups. The mean age of the patients, in harmonic scalpel group, was $45.29 \pm 4.56$ years. There were $64.5 \%(n=20)$ males and $35.5 \%(n=11)$ females. The mean age of the patients, in conventional knot, was $44.96 \pm 2.97$ years. There were $74.2 \%(n=23)$ males and $25.8 \%(n=8)$ females. No significant difference was found for age $(\mathrm{t}=0.329, \mathrm{p}=0.743)$ and gender $\left(\chi^{2}=0.683, \mathrm{p}=0.409\right)$ in groups. (Table 1$)$.

The main outcome variables of this study were the time of procedure (minutes) and blood loss volume (ml). The mean time of procedure was $98.80 \pm 16.52$ minutes and $119.81 \pm 9.95$ minutes for the harmonic scalpel 
and conventional knot groups respectively. Significant difference was found for the time of procedure in groups $(\mathrm{t}=-6.060, \mathrm{p}$-value $=0.000)$. (table. 2$)$

The mean blood loss volume was $454.52 \pm 22.73 \mathrm{ml}$ and $850.68 \pm 23.79 \mathrm{ml}$ for the harmonic scalpel and conventional knot groups respectively. Significant difference was found for the blood loss volume in groups $(\mathrm{t}=-$ 67.025, p-value $=0.000)$. (table. 2$)$

Table. 1

\section{Demographic Variables}

\begin{tabular}{|l|c|c|c|}
\hline Variable & $\begin{array}{c}\text { Harmonic Scalpel } \\
(\mathbf{n}=\mathbf{3 1})\end{array}$ & $\begin{array}{c}\text { Conventional Knot } \\
(\mathbf{n}=\mathbf{3 1})\end{array}$ & Test of sig. \\
\hline Age & $45.29 \pm 4.56$ years & $44.96 \pm 2.97$ years & $\mathrm{t}=0.329, \mathrm{p}=0.743$ \\
\hline Gender & $\mathrm{M}=64.5 \%, \mathrm{~F}=35.5 \%$ & $\mathrm{M}=74.2 \%, \mathrm{~F}=25.8 \%$ & $\chi^{2}=0.683, \mathrm{p}=0.409$ \\
\hline
\end{tabular}

Table. 2

\section{Analysis of Variance}

\begin{tabular}{|l|c|c|c|}
\hline Variable & $\begin{array}{c}\text { Harmonic Scalpel } \\
(\mathbf{n}=\mathbf{3 1})\end{array}$ & $\begin{array}{c}\text { Conventional Knot } \\
(\mathbf{n}=\mathbf{3 1})\end{array}$ & Test of sig. \\
\hline Time of Procedure & $98.80 \pm 16.52$ minutes & $119.81 \pm 9.95$ minutes & $\mathrm{t}=-6.060, \mathrm{p}=0.000$ \\
\hline Blood loss Volume & $454.52 \pm 22.73 \mathrm{ml}$ & $850.68 \pm 23.79 \mathrm{ml}$ & $\mathrm{t}=-67.025, \mathrm{p}=0.000$ \\
\hline
\end{tabular}

\section{Discussion:}

As we know that bleeding control during thyroidectomy plays very important role during the whole surgical procedure. Uncontrolled blood loss during the process can cause disturbance in homeostatic stability and even could lead to death of patient. To find out which method either use of conventional knot tying or harmonic scalpel is useful for bleeding control in thyroidectomy ${ }^{[3]}$. But the results of current studies show that harmonic scalpel is much better than the conventional knot $^{[11]}$.

Many studies has conducted in the past, but almost no one study shows that conventional knot method is better comparative to harmonic but recent studies done with highly advanced technology shows that harmonic scalpel is much better than ligation ${ }^{[12]}$.

It was thought that technique of harmonic scalpel is beneficial as compare to conventional procedure .By using harmonic scalpel two major changes occur, first of all the time duration is reduced and second the risk of hypocalcaemia and recurrent laryngeal nerve paresis is reduced. From the beginning of this century a large number of persons did research on advantageous use of harmonic scalpel ${ }^{[13]}$. Some important studies are given below in this regard.

A study done in 2015 by Cheng et al, total number of $100 \%(n=86)$ patients were used to observe the reduction in time, or indirectly observe the significantly faster operative time $(-23.1 \mathrm{~min}, \mathrm{p}<0.001)$, and less transient hypocalcaemia (RR0.69, $\mathrm{p}=0.01$ ). The result of this study support our results.

Even after few years later another group of scientists did 11 studies, Zhang found significantly even more faster time $(-22.4 \mathrm{~min}, \mathrm{p}=0.001)$, time period is very necessary during thyroid gland surgery because the thyroid gland is highly vascularized gland that's why effective and meticulous homeostasis is required to decrease over bleeding. Finally the most recent study is done few year earlier by Blanchard et al, they use 25 patients during this study 11 male and 14 female were included, female and male were of equal age ${ }^{[14]}$. They found the operative time as $(-18.7 \mathrm{~min}, \mathrm{p}<0.001)^{[15]}$. 
Other major advantage of using harmonic scalpel is that it reduces the blood volume and post-operative pain. Many persons do study on this issue some of these are given below.

Duan et al use total number of $100 \%(n=28)$ patients for this case and do 13 experiments to find the clear results. The results of these experiments on 28 patients show the blood volume loss during operation by harmonic scalpel is $(-14.4 \mathrm{ml} \mathrm{p}<0.001)$ this is intra operative blood loss. Similarly drainage $(-7.5 \mathrm{ml}, \mathrm{p}<0.001)$, and lower hospitalization charges $(-118 \mathrm{USD}, \mathrm{p}<0.001)^{[16]}$.

In very recent days, two Newton meta-analyses have been done. These studies show, harmonic scalpel was compared with conventional knot ligation and bipolar technology. Each of these Newton meta-analyses , contains 21 studies and finds very fast operative time $(-22.3 \mathrm{~min}, \mathrm{p}<0.001)$ less post-operative bleeding, short hospital stay $(-0.28$ days, $\mathrm{p}=0.001)$ and $)$ less intraoperative blood loss $(-28.5 \mathrm{ml}, \mathrm{p}<0.001)^{[17]}$.

All the above studies were done on high level and no single study is done on local scale ${ }^{[18]}$. We study the process of thyroidectomy on local level and derived that bleeding control is very good by the use of harmonic techniques. On the other hand, the time period of surgery is also reduced. The results of our study done on local level almost resemble and these results are supported with above or recent studies that are done on larger scale and higher level ${ }^{[19]}$.

\section{Conclusion:}

The whole study can be ended with this conclusion that the harmonic scalpel is more effective than the conventional method of ligation or knotting in thyroidectomy. Its use offer many clinical benefits including reduction in time of surgery and blood volume as well.

\section{Recommendation:}

We recommended that if both harmonic as well as conventional techniques of thyroidectomy are available in the hospital at the surgery then harmonic technique is very suitable for both patient and surgeon.

\section{Limitation:}

This trial was designed on local level and small numbers of the patients were included in this trial. For better results and recommendations more studies are recommended of other population.

\section{Finding Source:}

Nil

\section{Conflict of Interest:}

Nil

\section{References:}

1. Kwak HY, Chae BJ, Park YG, Kim SH, Chang EY, Kim EJ, et al. Comparison of surgical outcomes between papillary thyroid cancer patients treated with the Harmonic ACE scalpel and LigaSure Precise instrument during conventional thyroidectomy: a single-blind prospective randomized controlled trial. Journal of Surgical Research, 2014. 187(2): 484-489.

2. Revelli L, Damiani G, Bianchi CB, Vanella S, Ricciardi W, Raffaelli M, et al. Complications in thyroid surgery. Harmonic Scalpel, Harmonic Focus versus Conventional Hemostasis: a meta-analysis. International Journal of Surgery, 2016. 28: S22-32.

3. Lang BH, Ng SH, Lau LL, Cowling BJ, Wong KP, et al. A systematic review and meta-analysis comparing the efficacy and surgical outcomes of total thyroidectomy between harmonic scalpel versus ligasure. Annals of surgical oncology, 2013. 20(6): 1918-1926.

4. Zanghì A, Cavallaro A, Di Vita M, Cardì F, Di Mattia P, Piccolo G, et al. The safety of the Harmonic ${ }^{\circledR}$ FOCUS in open thyroidectomy: a prospective, randomized study comparing the Harmonic ${ }^{\circledR}$ FOCUS and traditional suture ligation (knot and tie) technique. International Journal of Surgery, 2014. 12: S132-5. 
5. Hettlich BF, Cook L, London C, Fosgate GT. Comparison of harmonic blade versus traditional approach in canine patients undergoing spinal decompressive surgery for naturally occurring thoracolumbar disk extrusion. PloS one, 2017. 12(3): e0172822.

6. Chavez KV, Barajas EM, Ramírez J, Pantoja JP, Sierra M, Velázquez-Fernandez D, et al, Comparative analysis between a bipolar vessel sealing and cutting device and the tie and suture technique in thyroidectomy: a randomized clinical trial. Surgery, 2017. 161(2): 477-484.

7. Docimo G, Tolone S, Conzo G, Limongelli P, Del Genio G, Parmeggiani D, et al. A Gelatin-Thrombin Matrix Topical Hemostatic Agent (Floseal) in Combination With Harmonic Scalpel Is Effective in Patients Undergoing Total Thyroidectomy: A Prospective, Multicenter, Single-Blind, Randomized Controlled Trial. Surgical Innovation, 2016. 23(1): 23-9.

8. Cannizzaro MA, Borzì L, Lo Bianco S, Okatyeva V, Cavallaro A, Buffone A. Comparison between Focus Harmonic scalpel and other hemostatic techniques in open thyroidectomy: A systematic review and meta-analysis. Head \& Neck, 2016. 38(10): 1571-1578.

9. Yener O, Demir M, Yılmaz A, Yıgıtbaşı R, Atak T. Harmonic scalpel compared to conventional hemostasis in thyroid surgery. Indian Journal of Surgery. 2014. 76(1):66-69.

10. Cheng H, Soleas I, Ferko NC, Clymer JW, Amaral JF. A systematic review and meta-analysis of Harmonic Focus in thyroidectomy compared to conventional techniques. Thyroid Research. 2015;1(8): 15 .

11. Zhang L, Li N, Yang X, Chen J. A meta-analysis comparing the outcomes of LigaSure Small Jaw versus clamp-and-tie technique or Harmonic Focus Scalpel in Thyroidectomy. Medicine (Baltimore). 2017 Mar;96(11):e6141.

12. Carlander J, Wagner P, Gimm O, Nordenström E, Jansson S, Bergkvist L. Risk of complications with energy-based surgical devices in thyroid surgery: A national multicenter register study. World Journal of Surgery. 2016;40(1): 117-123.

13. Chen, C, Cavanaugh JM, Kallakuri S, Tanimoto K, Broughton D, Clymer JW, et al. Acute Effects of Ultrasonic Shears and Monopolar Electrosurgery on Sciatic Nerve Electrophysiology. 2016; British Journal of Medicine \& Medical Research 14(12): 1-8.

14. Blanchard C, Pattou F, Brunaud L, Hamy A, Dahan M, Mathonnet M, et al. Randomized clinical trial of ultrasonic scissors versus conventional haemostasis to compare complications and economics after total thyroidectomy (FOThyr). BJS Open. 2017;1:2-10.

15. Cheng H, Hsiao CW, Clymer JW, Schwiers ML, Tibensky BN, Patel L, et al. Gastrectomy and D2 lymphadenectomy for gastric cancer: a meta-analysis comparing the harmonic scalpel to conventional techniques. International journal of surgical oncology. 2015; 2015:397260.

16. Duan Yf, Duan YF, Xue W, Zhu F, Sun DL. FOCUS harmonic scalpel compared to conventional hemostasis in open total thyroidectomy-a prospective randomized study. J Otolaryngol Head Neck Surg. 2013 Dec 20;42:62.

17. Çiftçi F. The comparison of the harmonic focus shears device with conventional clamp binding in total thyroidectomy. International journal of clinical and experimental medicine, 2015;8(10): 19266-73.

18. Coiro S, Frattaroli FM, De Lucia F, Manna E, Fabi F, Frattaroli JM, et al. A comparison of the outcome using Ligasure ${ }^{\mathrm{TM}}$ small jaw and clamp-and-tie technique in thyroidectomy: a randomized single center study. Langenbeck's archives of surgery, 2015. 400(2): 247-52.

19. He QQ, Zhu J, Zhuang DY, Fan ZY, Zheng LM, Zhou P, et al. Comparative study between robotic total thyroidectomy with central lymph node dissection via bilateral axillo-breast approach and conventional open procedure for papillary thyroid microcarcinoma. Chinese Medical Journal. 2016; 129(18): 2160-6. 